\title{
URGENSI DAN SIGNIFIKANSI MURSYID BAGI MURID DALAM TAREKAT
}

\author{
A.R. Iga Megananda Pratama \\ STAI Al-Amin Indramayu
}

\begin{abstract}
Abstrak : Tarekat dalam bentuknya sebagai organisasi yang didalamnya diajarkan tentang pencapaian kerohanian ke tingkat yang bisa membuat pelaku tarekat (salik) sampai berada sedekat mungkin dengan Tuhan. Maka dalam tarekat yang demikian akan ditemukan istilah mursyid dan murid. Istilah mursyid memiliki arti guru, yaitu guru yang mengajarkan tentang suatu ajaran tarekat, dan membimbing murid untuk bisa berada sedekat mungkin dengan Tuhan. Sedangkan murid adalah para pencari jalan kebenaran menuju Tuhan yang belajar tarekat pada syeikh atau mursyid dari suatu tarekat. Eksistensi mursyid dalam suatu tarekat sangat penting dan memiliki peran yang sentran serta dominan dalam mengantarkan muridnya untuk berada sedekat mungkin dengan Tuhan. Hubungan antara murid dengan mursyid begitu istimewa dan sangat sentral, bahkan sampai pada tingkat yang perlu dikritisi karena dikhawatirkan dapat mengarah kepada titik yang perlu dipertanyakan secara akidah dan keimanan.
\end{abstract}

Kata Kunci: Mursyid, Murid, dan Tarekat

\section{A. Pendahuluan}

Istilah tarekat sesungguhnya mempunyai dua macam pengertian, yaitu: Pertama, tarekat yang diartikan sebagai pendidikan kerohanian yang sering dilakukan oleh orang-orang yang menempuh kehidupan tasawuf, untuk mencapai suatu tingkatan kerohanian yang disebut " almaqâmat, dan al-ahwâl. Pengertian yang seperti ini, menonjol sekitar abad ke-IX dan ke-X Masehi. Kedua; tarekat yang diartikan sebagai perkumpulan yang didirikan menurut aturan yang telah dibuat oleh syekh yang menganut suatu aliran tarekat tertentu. Maka dalam perkumpulan itulah seorang syekh yang menganut suatu aliran yang 
mengajarkan ilmu tasawuf menurut aliran tarekat yang dianutnya, lalu diamalkan bersama dengan murud-muridnya. Pengertian yang seperti ini, menonjol sesudah abad ke IX Masehi. ${ }^{1}$

Dalam tarekat yang diartikan sebagai pendidikan kerohanian yang sering dilakukan oleh orang-orang yang menempuh kehidupan tasawuf, untuk mencapai suatu tingkatan kerohanian yang disebut "almaqâmat, dan al-ahwâl ini dikenal adanya istilah mursyid dan murid. Mursyid adalah sebutan bagi guru dalam tarekat sedangkan sebutan untuk yang belajar tarekat kepada mursyid disebut dengan istilah murid. Dalam tarekat, antara guru dan murid mempunyai aturan dan kewajiban yang harus dipatuhi dan dilaksanakan secara ketat. Begitu pula dalam kaitan ini, ada Adab yang harus dilaksanakan seperti adab murid terhadap mursyid, dan adab murid terhadap dirinya sendiri dan terhadap sesama ikhwan dalam tarekat.

\section{B. Pembahasan}

\section{Pengertian Tarekat}

Kata tarekat secara etimologis memiliki beberapa arti, yaitu (1). Jalan, cara (al-kaifiyyah); (2). Metode, sistem (al-Uslub); (3). Madzhab, aliran, haluan (al-madzhab); (4). Keadaan (al-hallah). (5). Pohon Kurma yang tinggi (an-nakhlal at-tawilah). (6). Tiang tempat berteduh), tongkat payung ('amud al-mizallah). (7). Yang mulia, terkemuka dari kaum (syarif al-qaum). (8). Goresan/ Garis pada sesuatu (al-khat fi al-asy-syay). ${ }^{2}$

Aboebakar Atjeh menerangkan bahwa tarekat artinya jalan, petunjuk dalam melakukan suatu ibadah sesuai dengan ajaran yang diturunkan dan dicontohkan oleh Nabi dan dikerjakan oleh sahabat dan tabi'in, turun temurun sampai kepada guru-guru, sambung menyambung dan rantai-merantai. ${ }^{3}$

Kata tarekat dalam Kamus Munjid berasal dari bahasa Arab al-thariqah berarti jalan, keadaan, aliran atau garis pada

\footnotetext{
hlm., 281-282

${ }^{2}$ Dewan Redaksi Ensiklopedi Islam. Ensiklopedi Islam 5. Jakarta: Ikhtiar Baru. 1997., hlm., 66

${ }^{3}$ Aboebakar Atjeh, Pengantar Ilmu Tarekat: Uraian-uraian tetang Mistik (Solo: Ramadhani, 1990), hlm., 67.
}

${ }^{1}$ H.A Mustofa. Akhlak Tasawuf. Bandung : Penerbit CV. Pustaka Setia. 1997. 
sesuatu. ${ }^{4}$ Dengan demikian tarekat adalah jalan yang ditempuh oleh para sufi yang berpangkal pada syari'at, sebab jalan utama dalam bahasa Arab disebut Syari' sedangkan anak jalan disebut thariq. Kata turunan ini menunjukkan bahwa menurut anggapan para sufi, pendidikan mistik yang dikenal dengan tasawuf merupakan cabang dari jalan utama yang dikenal dengan syari'ah/hukum yang dijadikan sebagai tempat berpihak bagi setiap muslim.

Tarekat menurut pendapat Harun Nasution, ${ }^{5}$ berasal dari Thariqah, yaitu jalan yang harus ditempuh seorang calon sufi dalam tujuannya berada sedekat mungkin dengan Tuhan. Tarekat kemudian mengandung arti organisasi (tarekat), dan tiap-tiap tarekat mempunyai syekh, upacara ritual, dan bentuk dzikir, dan wirid sendiri. Namun, dari sekian banyak ragam jenis wirid, nampaknya yang paling banyak digemari dan diamalkan tarekat, ada tiga macam lafadz wirid, yaitu: wirid istighfar, wirid shalawat, dan wirid dzikir. ${ }^{6}$

Kata tarekat menurut pendapat J. Spencer Trimingham tarekat adalah suatu metode praktis untuk menuntun atau membimbing seseorang murid secara berencana dengan jalan pikiran, perasaan dan tindakan, terkendali terus menerus kepada suatu rangkaian dari tingkatan-tingkatan (maqamal) untuk dapat merasakan hakekat yang sebenarnya. ${ }^{7}$

Istilah tarekat paling tidak dipakai untuk dua hal yang secara konseptual berbeda. Pada awalnya tarekat ini merupakan paduan yang khas dari doktrin, metode dan ritual. Akan tetapi istilah ini sering juga dipakai untuk mengacu kepada organisasi yang menyatukan pengikut jalan tertentu. Dalam hal ini istilah thaifah lebih dikenal di daerah Timur Tengah lebih dari pada tarekat dalam pengertian organisasi, dengan demikian mudah bagi

${ }^{4}$ Louis Ma'luf. Al-Munjid Fi Al-Lughah Wa Al-'Alam. Beirut : dar Al-Masyrik. 1975: 465.

5 Harun Nasution, Falsafah dan Mistisisme dalam Islam, (Jakarta: Bulan Bintang, 1986)., hlm., 89.

${ }^{6}$ H.A. Rivay Siregar, Tasawuf : Dari sufisme klasik Ke Neo-Sufistik, hlm., 274 Press, 973)

${ }^{7}$ Trimingham J. Spencer, The Sufi Orders in Islam (London: Oxford University 
mereka untuk membedakan antara tarekat yang mengandung pengertian jalan, cara dengan tarekat yang mengandung arti organisasi. Akan tetapi di Indonesia istilah tarekat mengacu kepada kedua pengertian tersebut.

L. Massignon. menjelaskan bahwa istilah tarekat mempunyai dua macam pengertian, yaitu: Pertama, tarekat yang diartikan sebagai pendidikan kerohanian yang sering dilakukan oleh orang-orang yang menempuh kehidupan tasawuf, untuk mencapai suatu tingkatan kerohanian yang disebut "al-maqâmat, dan al-ahwâl. Kedua; tarekat yang diartikan sebagai perkumpulan yang didirikan menurut aturan yang telah dibuat oleh syekh yang menganut suatu aliran tarekat tertentu. Maka dalam perkumpulan itulah seorang syekh yang menganut suatu aliran yang mengajarkan ilmu tasawuf menurut aliran tarekat yang dianutnya, lalu diamalkan bersama dengan murud-muridnya.. ${ }^{8}$

Di kalangan Muhadditsin tarikat digambarkan dalam dua arti yang asasi. Pertama, menggambarkan sesuatu yang tidak dibatasi terlebih dahulu (lancar), dan kedua, didasarkan pada sistem yang jelas yang dibatasi sebelumnya. Selain itu tarikat juga diartikan sekumpulan cara-cara yang bersifat renungan, dan usaha inderawi yang mengantarkan pada hakikat, atau sesuatu data yang benar. $^{9}$

Melacak secara historisnya, kapan dan tarekat mana yang mula-mula muncul sebagai suatu lembaga, tampaknya sulit diketahui dengan pasti. Menurut Harun Nasution, setelah AlGhazali menghalalkan tasawuf yang sebelumnya dikatakan sesat, tasawuf akhirnya berkembang di dunia Islam melalui tarekat. Tarekat ialah organisasi dari pengikut sufi-sufi besar yang bertujuan untuk melestarikan ajaran tasawuf gurunya. Tarekat ini memakai suatu tempat pusat kegiatan yang disebut ribath atau zauwiyah. $^{10}$

${ }^{8}$ H.A Mustofa. Akhlak Tasawuf. Bandung : Penerbit CV. Pustaka Setia. 1997., hlm., 281-282

9 Jamil Shaliba, Al-Mu'jam al-Falsafi, Juz II, (Beirut: Dar al-Kitab, 1979), hlm.20.

${ }^{10}$ Harun Nasution, "Perkembangan Ilmu Tasawur di Dunia Islam", dalam Orientasi Pengemhangan Ilmu Tasawuf: Proyek pemhinaan Prasarana dan Sarana 


\section{Kode Etik Tarekat}

Tarekat sebagai suatu organisasi memiliki mursyid dan murid/ Dalam tradisi tarekat, otoritas mursyid atau guru terhadap murid sangat dominan sehingga ia dapat membentuk karakter muridnya sesuai dengan sasaran yang ingin dicapai. Oleh karena tarekat adalah sarana perjalanan menuju Allah maka harus ada pola hubungan yang ketat antara guru dan murid untuk terciptanya satu disiplin dalam kehidupan bersama. ${ }^{11}$

Sistem hubungan antara mursyid dan murid menjadi fondasi bagi pertumbuhan tarekat sebagai sebuah organisasi dan jaringan. $^{12}$ Fungsi mursyid yang demikian sentral sebagai pembimbing rohani dalam rangka menjalani maqamat, menjadikan murid secara alami menerima otoritas dan bimbingannya.

Penerimaan ini tampaknya didasarkan atas keyakinan bahwa setiap manusia mempunyai kemungkinan yang inheren dalam dirinya berupa kemampuan untuk mewujudkan proses dan pengalaman "bersatu" dengan Tuhan. Akan tetapi, potensi ini terpendam dan dapat terwujud hanya dengan iluminasi tertentu yang dianugerahkan oleh Tuhan, tanpa bimbingan dan seorang mursyid.

Tarekat, dalam proses bimbingan di atas, pada mulanya adalah suatu metode praktis —yang biasanya sejajar dengan istilah-istilah lain seperti mazhab, ri'ayah, dan suluk. Kemudian tarekat berkembang yang bertujuan membimbing seorang pencari dengan menelusuri suatu jalan berpikir, merasa, dan bertindak melalui urutan maqamat dan ahwal menuju pengalaman tentang realitas Ilahi. Dengan demikian, sebagaimana dikemukakan oleb J. Spencer Trimingham, pada awalnya tarekat berarti sekadar metode gradual mistisisme kontemplatif dan pelepasan diri. Sekelompok murid berkumpul mengelilingi seorang guru sufisme

Perguruan Tinggi Agama Islam/IAIN di Jakarta, (Depag RI, 1986), hlm. 24. Lihat pula Rosihon Anwar dan Mukhar Solihin, Ilmu Tasawuf, (Bandung: Pustaka Setia, 2000), hlm. 167.

${ }^{11}$ H.A. Rivay Siregar, Tasawuf : Dari sufisme klasik Ke Neo-Sufistik, hlm., 269

12 J. Spencer Trinun«hrtm, The Suji Orderer in Islam, (London: Oxford University Press, 1973. hlm. 5. 
terkenal, mencari pelatihan melalui persatuan dan kebersamaan yang awalnya belum mengenal ucapan spesifik dan prosesi baiat apa pun. ${ }^{13}$

Dalam tarekat, komitmen seorang murid tidak cakup hanya sekedar belajar dan beramal, tetapi juga diharuskan menjaga tatakrama dan loyalitas kepada guru agar ilmu yang didapat itu diberkati. Dari sekian banyak tata aturan dan pola hubungan dalam tarekat, dapat dianggap sebagai kode etik yang dapat dirumuskan dalam beberapa hal yang penting, antara lain:

1. Ketaatan dan kepatuhan kepada guru secara utuh, baik sewaktu berada di lingkungan ribath maupun di tempat lain.

2. Menjaga dan mengawal kehormatan guru, baik sedang berhadapan maupun berjauhan, semasa guru hidup maupun sesudah meninggalnya.

3. Murid dilarang membantah ajaran guru walaupun bertentangan dengan pendapatnya. Apa ajaran guru harus diikuti. ${ }^{14}$

Selanjutnya, menurut Rivay siregar setiap murid diharuskan meng-ikuti aturan dasar tarekat, antara lain:

1. Wajib mempelajari syariat Islam sedaya mampu, baik yang berkenan dengan akidah, ibadah maupun muamalah.

2. Tidak boleh mencari-cari keringanan dalam beribadah.

3. Mengisi waktu dengan wirid dan doa sebanyak mungkin agar selalu ingat pada Allah.

4. Mengendalikan hawa nafsu, karena hawa nafsu dapat merusak kesucian jiwa.

5. Menghindari segala sesuatu yang dapat merangsang hawa nafsu, karena dorongan hawa nafsu lebih banyak ke arah yang tidak baik. ${ }^{15}$

Selain daripada itu, lebih lanjut rivay Siregar menjelaskan bahwa murid mempunyai tugas pokok yang tidak boleh diabaikan, yaitu:

${ }^{13}$ Samsul Munir Amin. Ilmu Tasawuf. Jakarta: Remaja rosdakarya. 2015.., hlm., 298

${ }^{14}$ Ibid., hlm., 269-270

15 Ibid., hlm., 270 
1. Tetap memelihara ketakwaan kepada Allah dengan melaksanakan kewajiban dan meninggalkan larangan-Nya.

2. Beramal dengan segala macam amalan yang dapat menyempurnakan kesucian jiwa.

3. Senantiasa bersikap wara' atau hati-hati dalam setiap tindakan.

4. Bergaul dengan orang-orang saleh dan ulama, berusaha menjauhi orang yang mengejar kenikmatan du-niawi semata.

5. Senantiasa berakhlak karimah dan sopan santun terhadap sesama.

6. Efisien dalam penggunaan waktu.

7. Menjaga diri agar selalu dekat dengan Allah-muraqabah.

8. Ikhlas dalam melaksanakan pekerjaan.

9. Senantiasa berusaha meningkatkan kepekaan hati dan menjauhkan diri dari apa saja yang mungkin dapat mengotori jiwa dengan selalu menyadari, bahwa: dunia ini adalah persinggahan sementara, tujuan akhir perjalanan adalah akhirat,

10. Selalu ingat mati,

11. Allah selalu mengawasi dirinya

12. Jiwa itu sifatnya labil, mudah berubah. ${ }^{16}$

Memperhatikan prinsip-prinsip tcrsebut diatas, nampaknya masalah kebersamaan adalah salah salu asas yang penting dalam kehidupan tarekat. Kesamaan arah dan kesatuan komando di bawah kepemimpinan syekh tarekat, merupakan persoalan mendasar dalam kehidupan tarekat, termasuk dalam perjalanan spiritual menuju Allah. Oleh karena itu, dalam tradisi tarekat tidak ditolerir adanya perbedaan visi dan misi tetapi harus selalu berada dalam satu formasi sesuai dengan arahan dan fatwa syekh tarekat. ${ }^{17}$

Menurut ketentuan tarikat pada umumnya, bahwa seorang syaikh sangat menentukan terhadap muridnya. Keberadaan murid di hadapan gurunya ibarat mayit atau bangkai yang tak berdaya apa-apa. Dan karena tarikat itu merupakan jalan yang harus dilalui untuk mendekatkan diri kepada Allah, maka orang yang

${ }^{16}$ Ibid., hlm., 270-271

${ }^{17}$ Ibid., hlm., 272 
menjalankan tarikat itu harus menjalankan syariat dan si murid harus memenuhi unsur-unsur sebagai berikut:

a. Mempelajari ilmu pengetahuan yang berkaitan dengan syariat agama.

b. Mengamati dan berusaha semaksimal mungkin untuk mengikuti jejak langkah guru; melaksanakan perintahnya dan meninggalkan larangannya.

c. Tidak mencari-cari keringanan dalam beramal agar tercapai kesempurna-an yang hakiki.

d. Berbuat dan mengisi waktu seefisien mungkin dengan segala wirid dan doa guna pemantapan dan kekhusuan dalam mencapai maqomat (stasiun) yang lebih tinggi.

e. Mengekang hawa nafsu agar terhindar dari kesalahan yang dapat menodai amal. ${ }^{18}$

Ciri-ciri tarikat tersebut merupakan ciri yang pada umumnya dianut setiap kelompok, sedangkan dalam bentuk amal dan wiridnya berbeda-beda.

Dengan ciri-ciri tarikat yang demikian itu, menurut Abuddinata tidak mengherankan jika ada pendapat yang mengatakan bahwa tarikat sebenarnya termasuk dalam ilmu mukasyafah, yaitu ilmu yang dapat menghasilkan pancaran nur (cahaya) Tuhan ke dalam hati murid-muridnya, sehingga dengan nur (cahaya) itu terbukalah baginya segala sesuatu yang gaib daripada ucapan-ucapan nabinya dan rahasia-rahasia Tuhannya. Ilmu ini dilakukan dengan cara riyadah/latihan dan mujahadah. ${ }^{19}$

\section{Pengertian Mursyid}

Mursyid adalah istilah atau sebutan syeikh dalam suatu tarekat. Istilah mursyid ini mempunyai arti guru, yakni guru yang mengajarkan suatu tarekat tertentu kepada murid-muridnya yang sedang menuntut ilmu dalam suatu tarekat tertentu

Guru atau mursyid dalam sistem tasawuf adalah asrâfu alnasi fî at-thariqoh artinya orang yang paling tinggi martabatnya

${ }^{18}$ Abuddinata., Akhlak Tasawuf dan karakter Mulia. Jakarta : PT. Raja Grapindo Persada. 2014., hlm., 235

${ }^{19}$ Ibid., 
dalam suatu tarekat. Mursyid mengajarkan bagaimana cara mendekatkan diri kepada Allah sekaligus memberikan contoh bagaimana ibadah yang benar secara syari'at dan hakikat. ${ }^{20}$

\section{Kriteria Mursyid}

Menjadi seorang mursyid tentu tidaklah mudah, karena untuk menjadi seorang mursyid harus memenuhi kriteria tertentu. Kriteria mursyid adalah:

a. $\quad$ Seorang mursyid haruslah seorang alim

b. Seorang mursyid haruslah 'arif

c. Seorang mursyid harus sabar dan mempunyai rasa belas kasihan yang tinggi kepada murid-muridnya

d. Seorang mursyid harus pandai menyimpan rahasia muridmuridnya.

e. Seorang mursyid tidak boleh menyalahgunakan kedudukan sebagai seorang guru spiritual atau orang yang paling tinggi martabatnya dalam tarekat.

f. Seorang mursyid haruslah bijaksana.

g. Seorang mursyid harus disiplin

h. Menjaga lisan dan nafsu keduniaan.

i. Seorang mursyid harus mempunyai hati yang ikhlas.

j. Selalu menjaga jarak antara dirinya dengan muridnya.

k. Memelihara harga diri, wibawa dan kehormatan.

1. Mursyid harus bisa memberi petunjuk tertentu pada situasi tertentu kepada muridnya.

m. Merahasiakan hal-hal yang istimewa.

n. Mursyid selalu mengawasi muridnya dalam kehidupan seharihari.

o. Merahasiakan segala gerak gerik kehidupannya.

p. Seorang mursyid harus mencegah berlebihan dalam makan dan minum.

q. Seorang mursyid harus menyediakan tempat berkhalwat bagi murid-muridnya.

r. Menutup pergaulan murid dengan mursyid yang lain. ${ }^{21}$ hlm. 145

${ }^{20}$ Cecep Alba. Cahaya Tasawuf. Bandung : CV. Wahana Karya Grafika. 2009., 
Amin Kurdi dalam bukunya Tanwîr al-Qulûb, sebagaimana dikutip oleh Cecep Alba, ${ }^{22}$ mengutarakan kriteria mursyid sebagai berikut:

a. Seorang mursyid hendaklah mengetahui hukum fikih dan tauhid yang diperlukan oleh para pengikut jalan ruhani sekedar untuk menghilangkan ketidakjelasan yang diajukan oleh seorang pengikut mubtadi sehingga ia tidak perlu bertanya kepada yang lain.

b. Mengenal berbagai kesempurnaan hati, etika-etikanya, wabah dan penyakit jiwa serta cara menjaga kesehatan dan kesetabilannya.

c. Bermurah hati dan berbelas kasih kepada kaum muslimin, khususnya kepada murid. Misalnya jika ia memandang muridmurid tak mampu melakukan pengendalian nafsu dan meninggalkan kebiasaan-kebiasaan buruk, haruslah ia bersikap arif dan toleran dan tidak membuat mereka putus asa dari melakukan suluk. la bergaul dengan mereka dengan rahmah sehingga mereka mendapat hidayah.

d. Menutup aib para murid yang terlihat olehnya.

e. Bersih hati terhadap harta para murid, serta tidak tamak terhadap sesuatu yang mereka miliki.

f. Menyebarkan apa yang diperintahkan Allah dan mencegah apa yang di-larang-Nya dengan kata yang berkesan dalam jiwa para murid.

g. Tidak duduk bersama murid-muridnya kecuali hanya sekedar yang diperlukan. la selalu mengingatkan mereka pada beberapa ajaran tarekat dan syariat, agar mereka bersih dari kejelekan bisikan-bisikan hawa nafsu dan godaan setan juga agar mereka beribadah dengan cara yang benar.

h. Ucapannya bersih dari campuran-campuran hawa nafsu, senda gurau yang berlebihan dan sesuatu yang tidak bermakna.

${ }^{21}$ Ibid., hlm. 146-147

${ }^{22}$ Ibid., hlm. 147-151. Kriteria Mursyid menurut pendapat al-Junaid al-Baghdadi adalah; harus menguasai ilmu syar'i, menjauhi yang haram, zuhud dalam hidup di dunia, dan qana'ah. Baca. Zamakhsyari Dhofier . Tradisi Pesantren. Jakarta : LP3ES .1994., hlm. 141 
i. Sangat toleran terhadap hak-hak dirinya serta tidak mengharapkan dimuliakan atau dihormati. la juga tidak menuntut haknya dari para murid dengan sesuatu yang mereka tidak mampu melakukannya, tidak mem-persiapkan amalanamalan yang membuat mereka jemu.

j. Jika melihat salah seorang muridnya di dalam hatinya hilang rasa hormat dan wibawa karena banyak duduk dan bergaul bersamanya, dia menyuruh-nya duduk berkhalwat di tempat yang tidak begitu jauh dan juga tidak begitu dekat, tetapi di antara keduanya.

k. Apabila ia tahu bahwa penghormatan kepadanya jatuh dari hati seorang murid, ia mengubahnya dengan penuh kasih sayang, sebab hal tersebut merupakan musuh yang paling besar.

1. Tidak lalai dalam membimbing murid menuju sesuatu yang dapat mem-perbaiki kondisi ruhaninya.

m. Apabila seorang murid mensifati mimpi atau ketersingkapan (mukâsyafah) atau penyaksian gaib (musyâhadah) yang didapatinya kepada syaikh, ia tidak membicarakan rahasia yang tersimpan di bailik itu padanya, tetapi memberinya tambahan amalan yang dapat mendorong dan menaikannya pada tahapan ruhani yang lebih tinggi dan lebih mulia. Kapan saja syaikh membicarakan atau menjelaskannya, sungguh hal tersebut dalam hak syaikh merupakan satu kesalahan, sebab si murid akan memandang dirinya tinggi sehingga tingkatan ruhaninya justru akan jatuh.

n. Mencegah murid-muridnya berbicara dengan orang-orang selain ikwan (saudara seperguruannya) kecuali karena darurat. Juga mencegah berbicara dengan ikwannya mengenai karomat dan hal-hal yang datang kepada mereka. Apabila dalam hal tersebut syaikh bersikap toleran, ia benar-benar melakukan kesalahan sebab bisa membuat mereka arogan dan angkuh sehingga menyebabkan mereka terlambat.

o. Selalu berkhalwat menyendiri dan tidak mengizinkan seorang murid pun masuk menemuinya kecuali orang yang khusus 
baginya. Juga berkhalwat dengan cara berkumpul bersama sahabat-sahabatnya.

p. Sama sekali tidak mengizinkan muridnya melihat-lihat setiap gerakannya, mengetahui rahasianya, mencari tahu tentang cara tidur, cara makan, cara minum dan lain-lain. Sang murid, bila mencari tahu tentang hal-hal tersebut, barangkali akan berkurang rasa hormat pada syaikhnya oleh sebab kelemahan si murid dalam mengctahui kondisi ruhani orang-orang besar yang sempurna. Apabila syaikh melihat seorang murid memata-matai dirinya guna mencari tahu tenttang hal-hal tersebut, dia melarangnya demi kemaslahatan si murid itu sendiri.

q. Selamanya tidak toleran terhadap murid yang banyak makan, sebab apabila toleran dapat merusak segala hal yang sedang ia lakukan bagi sang murid, dan dikhawatirkan menjadi seperti banyak orang yang menjadi hamba sahaya bagi perutnya.

r. Melarang sahabat-sahabatnya bergaul dengan sahabat-sahabat syaikh lain sebab bahayanya bagi para murid sangat cepat. Kecuali bila syaikh melihat mereka tetap mencintainya dan tidak dikhawatikan terjadi kegoncangan. Jika demikian adanya maka tidaklah berbahaya.

s. Menjaga diri dari bolak balik kepada penguasa (umara) agar tidak dicontoh oleh murid-muridnya. Kalau demikian, ia harus menanggung dosanya dan dosa mereka yang mencontohnya. ${ }^{23}$ Hal demikian, sebab orang yang mendekati penguasa, biasanya akan sulit baginya menyampaikan penolakan jika penguasa melakukan perbuatan haram. Seakan mondar mandirnya kepada penguasa memberi legalitas pada kemunkaran.

t. Pembicaraannya kepada para murid dilakukan dengan cara sangat kasih sayang. Dia sangat hati-hati dari mencaci dan memaki mereka agar jiwa mereka tidak lari menjauh darinya.

23 Sebagaimana dalam hadis dijelaskan: "Barang siapa membuat suatu kebiasaan jelek, maka ia harus menanggung dosanya dan dosa orang yang melakukannya" (H. R.. Muslim dan Tirmizi). 
u. Jika diundang oleh salah seorang muridnya, ia memenuhinya dan melakukan-nya dengan cara terhormat serta menjauhkan diri dari hal-hal yang tidak baik atau bersikap 'iffah.

v. Apabila duduk di hadapan murid-muridnya, ia duduk dengan tenang dan berwibawa. la tidak banyak melirik mereka, tidak tidur dan tidak membentangkan kaki di hadapan mereka. la menahan pandangan dan merendahkan suaranya. la tidak menjelek-jelekan akhlaknya di hadapan mereka, sebab pada kenyataannya mereka meyakini seluruh sifat-sifat terpuji berada padanya dan mereka akan menirunya.

w. Jika seorang murid masuk menemuinya, ia tidak bermuka masam. Jika ia berpamitan pulang, ia mendoakannya tanpa diminta terlebih dahulu. Sebaliknya, jika ia masuk menemui salah seorang muridnya, ia berada dalam keadaan paling sempurna dan kondisi jiwa yang paling baik.

x. Jika salah seorang muridnya tidak hadir, ia bertanya tentangnya dan mencari tahu alasan tentang ketidakhadirannya. Jika si murid tadi sakit, ia menengoknya. Jika si murid ada dalam hajat, ia membantunya. Jika murid gaib karena uzur, maka ia mendo'akannya.

\section{Murid}

\subsection{Pengertian Murid}

Murid secara etimologis artinya orang yang berkehendak, berkemauan dan mempunyai cita-cita. Murid dalam istilah tarekat adalah orang yang bermaksud menempuh jalan untuk dapat sampai ke tujuan yakni keridoan Allah. Secara institusional murid adalah pengikut suatu aliran tarekat yang menghendaki pengetahuan dan pengamalan tarekat yang bersangkutan. ${ }^{24}$

Dalam definisi lain, murid dalam tarekat adalah orang yang berkehendak untuk menempuh jalan tasawuf dibawah bimbingan seorang syeikh dengan ketaatan penuh. ${ }^{25}$

${ }^{24}$ Abdul Wahab Asy'rani. Al-Anwâr Al-Qudsiyyah. Bairut : Dar Al-Fikr. 1996.,

25 Ahmad Zahro. Tradisi Intelektual NU: Lajnah Bahtsul Masa'il 1926-1999. Yogyakarta : LKIS. 2004., hlm. 43 
Adapun tahapan-tahapan yang mesti dialami oleh murid dalam tarekat adalah: 1) mendengar, 2) memahami 3) mengetahui 4) menyaksikan, dan 5) ma'rifah. ${ }^{26}$

\subsection{Kewajiban Murid pada Mursyid}

Untuk mencapai tujuannya seorang murid, seperti telah dijelaskan, perlu guru, guru dimaksud adalah mursyid. Adapun kewajiban murid terhadap mursyidnya adalah sebagai berikut:

a. Menyerahkan diri lahir batin.

b. Murid harus menurut dan mematuhi perintah gurunya.

c. Murid tidak boleh menggunjing gurunya.

d. Seorang murid tidak boleh melepaskan ikhtiarnya sendiri.

e. Seorang murid harus selalu ingat kepada gurunya.

f. Seorang murid tidak boleh memiliki keinginan untuk bergaul lebih dalam dengan mursyidnya, baik untuk tujuan dunia maupun akhirat.

g. Seorang murid harus mempunyai keyakinan dalam hati.

h. Seorang murid tidak boleh menyembunyikan rahasia hatinya.

i. Murid harus memlihara keluarga dan kerabat gurunya.

j. Kesenangan murid tidak boleh sama dengan gurunya.

k. Seorang murid tidak memberi saran kepada gurunya.

1. Seorang murid tidak boleh memandang kekurangan gurunya.

$\mathrm{m}$. Seorang murid harus rela memberikan sebagian hartanya.

n. Seorang murid tidak boleh bergaul dengan orang yang dibenci gurunya.

o. Seorang murid tidak boleh melakukan sesuatu yang dibenci gurunya.

p. Seorang murid tidak boleh iri kepada murid lainnya.

q. Segala sesuatu yang menyangkut pribadinya harus mendapat izin dari gurunya.

r. Tidak boleh duduk pada tempat yang biasa dipakai duduk oleh gurunya. $^{27}$ hlm.69

${ }^{26}$ Abdul Wahab Asy'rani. Al-Anwâr Al-Qudsiyyah. Bairut : Dar Al-Fikr. 1996.,

27 Siddiq. Mengenal Ajaran Tarekat Dalam Aliran Tasawuf. Surabaya : Putra Pelajar. 2001., hlm.45 Lihat juga Cecep Alba. Cahaya Tasawuf, hlm. 151-152 
Syihabuddin Sukhrowardi menjelaskan bahwa ada lima belas macam perilaku (adab) seorang murid di hadapan mursyidnya. Kelima belas adab itu adalah sebagai berikut:

a. Keyakinan penuh pada syaikh dalam ajaran, bimbingan, dan penyuci-annya atas murid-muridnya.

b. Ketetapan hati yang sempurna untuk mendatangi syaikh.

c. Mematuhi perintah syaikh.

d. Tidak melawan. Seorang murid baik secara lahir maupun secara batin tidak boleh melawan kewibawaan mursyidnya.

e. Menafikan kehendak dan keinginannya sendiri.

f. Selalu menghargai pemikiran syaikh.

g. Mengacu pada pengetahuan syaikh dalam menjelaskan makna ber-bagai macam mimpi.

h. Menghormati ucapan syaikh.

i. Merendahkan suara di hadapan syaikh.

j. Menahan diri dari tindakan-tindakan di luar batas.

k. Mengetahui waktu yang tepat untuk berbicara dengan syaikh.

1. Menjaga batas kehormatannya sendiri.

m. Mampu menjaga rahasia-rahasia syaikh.

n. Mengungkapkan berbagai rahasianya sendiri kepada syaikh. Setiap keajaiban dan anugrah yang diberikan Allah kepadanya harus segera diceritakan kepada syaikhnya untuk memperoleh penjelasan dan penilaian dari syaikhnya.

o. Berbicara kepada syaikh sesuai dengan kadar pemahaman pendengar lainnya. $^{28}$

\subsection{Adab Murid terhadap Dirinya Sendiri}

a. Meninggalkan pergaulan dengan orang-orang yang jahat, sebaliknya bergaul dengan orang-orang pilihan.

b. Jika hendak berdzikir padahal ia telah memiliki keluarga dan telah beranak maka seyogyanya menutup pintu yang dapat menghalangi antara dia dengan istri dan anaknya.

28 Syihabuddin Suhrowardi. 'Awarif Al-Ma'arif. Edisi Terjemah. Jakarta : Pustaka Hidayah. 1998., hlm.46 Lihat juga Cecep Alba. Cahaya Tasawuf, hlm.152153 
c. Meninggalkan sikap berlebihan baik dalam urusan makan, minum, pakaian, hubungan suami istri. Kata al-Gazali, Allah menjadikan kelebihan makan, minum di dunia sebagai penyebab kerasnya hati dan lambannya fisik melakukan ketaatan dan mendengar nasihat.

d. Meninggalkan cinta dunia dan berfikir tentang kehidupan akhirat. Cinta kepada Allah tidak akan bersemi di hati jika di hati ada cinta kepada dunia.

e. Tidak tidur dalam keadaan junub, telapi sebaliknya selalu dalam keadaan suci punya wudu.

f. Tidak boleh toma (berharap) kepada apa yang ada di tangan manusia lain.

g. Jika rizki sulit didapat, dan hati manusia keras kepadanya, maka bersabarlah, sebab boleh jadi harta dunia berpaling dari murid ketika ia masuk dalam tarekat. Tidak jarang si murid berkata; aku tidak butuh apa-apa dalam tarekat lalu tidak sadar suatu waktu ia membatalkan janjinya maka selamanya ia tidak akan bahagia. Jadi apabila rizki sulit didapat, ketahuilah bahwa Allah hendak menguji murid dan ahirnya Allah melindungi murid dan membukakan mata hatinya.

h. Hendaklah ia melakukan muhasabah (introspeksi) dan mendorong jiwanya untuk mengamalkan tarekat.

i. Menyedikitkan tidur, terutama di waktu sahur sebab ia adalah waktu ijabah.

j. Menjaga diri agar hanya makan yang halal.

k. Membiasakan diri sedikit makan; tidak makan kecuali bila lapar dan berhenti makan sebelum kenyang.

1. Menjaga lisan dari ucapan yang tidak berguna dan menjaga hati dari getaran yang tidak perlu. Orang yang menjaga lisannya dan istiqamah hatinya maka akan terbukalah baginya rahasia-rahasia langit.

m. Memejamkan mata dari melihat muharramat, sebab melihat yang diharamkan bagaikan racun yang dapat membunuh dan racun itu ada di hatinya maka dihawatirkan ia membunuh dirinya lebih-lebih jika melihat muharramat dengan syahwat. 
n. Meninggalkan senda gurau yang berlebihan sebab ia dapat memati-kan hati danbisa mengakibatkan kezaliman.

o. Menyertai ikhwan yang mengalami kesulitan, ajak ia bicara tentang adab dalam bertarekat agar hatinya terbuka dan ia lepas dari kesulitan yang dideritanya.

p. Meninggalkan terbahak-bahak dalam ketawa sebab ia dapat memati-kan fungsi hati, oleh karena itu Rasulullah tidak tertawa dengan terbahak-babak tetapi ia hanya tersenyum saja.

q. Menghindari membabas keadaan hal ihwal orang lain.

r. Menjauhi kecintaan kepada kemuliaan, keagungan dan kekuasaan sebab ia bisa memutus jalan kepada Allah. Nabi bersabda: "Tidaklah dua serigala yang lapar yang mengancam binatang ternak, lebih berbahaya ketimbang keserakahan seseorang atas kemuliaan dan harta terhadap agamanya."

s. Hendaklah murid bersikap tawadhu' sebab tawadhu' dapat mengangkat martabat orang yang melakukannya.

t. Hendaklah ia bersikap khauf dan raja'. Takut oleh Allah sekaligus mengharap ampunanNya.

u. Membiasakan diri mengucapkan insya Allah jika bermaksud melakukan atau tidak melakukan sesuatu.

v. Menyembunyikan rahasia spiritual yang ia dapatkan dalam mimpinya atau dalam terjaganya kecuali kepada mursyidnya.

w. Seyogyanya si murid memiliki waktu tersendiri untuk berdzikir kepada Tuhannya dengan dzikir yang khusus yang ia terima dari gurunya tanpa ada penambahan atau pengurangan.

x. Janganlah merasa lambat terbukanya hijab kepadanya, tetapi beribadahlah kepada Allah, sama saja apakah Allah membuka mata hatinya sehingga ia bisa melihat rahasia langit atau tidak. ${ }^{29}$

${ }^{29}$ Cecep Alba. Cahaya Tasawuf, hlm.153-154 


\subsection{Adab Murid Terhadap Sesama Ikhwan atau Terhadap Muslim}

a. Mencintai ikhwan tarekat seperti ia mencintai dirinya sendiri.

b. Memulai mengucapkan salam, bersalaman, dan berbicara dengan bahasa yang menyenangkan jika bertemu dengan sesama ikhwan. Nabi bersabda: "Apabila dua orang muslim ber-musofahah (berjabat tangan) maka keduanya diampuni dosanya sebelum berpisah"

c. Bergaul sesama ikhwan dengan akhlak yang baik. ${ }^{30}$

d. Bersikap tawadhu' kepada ikhwan. ${ }^{31}$

e. Mencari keridaan mereka dan anda harus memandang mereka lebih baik dari pada anda sendiri, selanjutnya saling menolong dalam kebaikan dan takwa, mencintai Allah dan mendorong mereka dalam apa yang diridai Allah dan anda menunjuki mereka ke jalan yang benar. ${ }^{32}$

f. Menaruh kasih kepada semua ikhwan, normal kepada yang lebih besar dan sayang kepada yang lebih muda. ${ }^{33}$

${ }^{30}$ Nabi bersabda: Orang mukmin yang paling sempurna imannya adalah orang yang paling baik akhlaknya" (HR. Tirmizi dan Ibnu Hibban).

${ }^{31}$ Nabi bersabda: "Barangsiapa bertawadu' karena Allah maka Allah akan mengangkatnya ke martabat yang tinggi, ia merasa kecil padahal di mata manusia ia adalah seorang yang besar, barangsiapa yang takabur maka Allah akan merendahkannya, dimatanya ia besar padahal di mata manusia yang lain ia seorang yang kecil bahkan ia sungguh lebih hina ketimbang anjing atau babi"(HR.Ahmad, Bazzar dan Tabrani).

${ }^{32}$ Allah berfirman: Artinya: Bertolong menolonglah kamu dalam kebaikan dan ketakwaan, dan janganlah bertolong menolong dalam dosa dan permusuhan ".

Nabi bersabda: "Bila Allah menghendaki seorang pemimpin itu baik, maka ia akan mengangkat menteri yang benar, jika pemimpin lupa maka menteri mengingatkannya, dan apabila ia ingat maka ia menolongnya. Apabila Allah menghendaki selain itu, maka Allah memberi baginya pembantu yang lacut, apabila pemimpin lupa maka ia tidak akan mengingatkannya, dan apabila ia ingat ia tidak akan menolongnnya". HR.AbuDawud).

Nabi bersabda: "Bukanlah golonganku, orang yang tidak hormat kepada yang lebih tua dari kita dan menyayangi orangorang yang lebih kccil dari kita" (HR. Tirmizi)

Nabi bersabda: Tidaklah termasuk golongan umatku, orang yang tidak menaruh hormat kepada yang lebih tua dan tidak menaruh kasih sayang kepada yang di bawahnya" (HR. Timiizi). Dalam hadis qudsi Nabi menyalakan: Jika kamu menghendaki kasih sayang-Ku maka kasihanilah makhluk-Ku, barangsiapa yang tidak sayang kepada manusia maka Allah tidak akan sayang kepadanya" (H.R. Bukhari dan Muslim). 
g. Bersikap simpatik dan halus dalam upaya menasihati ikhwan jika mereka melakukan pelanggaran. ${ }^{34}$

h. Berbaik sangka kepada ikhwan. Bila kamu melihat aib pada seseorang maka ucapkanlah pada diri anda sendiri: Aib itu sebenarnya ada pada saya sebab seorang muslim adalah cermin bagi muslim yang lainnya.

i. Hendaklah menerima permintaan maaf ikhwan yang lain apabila ia minta maaf meskipun ia berdusta, sebab orang yang meminta maaf kepadamu secara terbuka meskipun batinnya marah maka sesungguh-nya orang itu telah taat kepadamu dan telah menghormatimu. ${ }^{35}$

j. Mendamaikan dua ikhwan yang bermusuhan. ${ }^{36}$

k. Bersikap benar kepada sesama ikhwan dalam segala kondisi dan jangan lupa mendo'akan mereka dengan ampunan meskipun mereka gaib (tidak ada di hadapan kita).

1. Memberi kelapangan kepada mereka dalam majlis.

m. Bertanya tentang nama kawan kita sekaligus nama ayahnya. $^{37}$

${ }^{34}$ Imam Syafi'i berkata: "Barangsiapa menasihati saudaranya secara rahasia maka ia telah menasihatinya dan memperbaikinya, barangsiapa menasihati saudaranya secara terang-terangan maka ia telah membuka kejelekannya dan mempermalukannya".

Nabi bersabda: Barangsiapa menyembunyikan kcsalahan saudaranya maka Allah akan menutupi kesalahannya, dan barangsiapa membuka kesalahan saudaranya maka Allah akan membuka kesalahannya sehingga ia membuka kejelekannya di rumahnya sendiri".

${ }^{35}$ Nabi bersabda: "Barangsiapa didatangi saudaranya sambil minta dibebaskan kesalahan dirinya, maka terimalah, apakah ia benar atau pura-pura, barangsiapa tidak mengerjakannya maka ia tidak akan mendatangi telagaku di hari kiamat". (HR. Hakim).

36 Allah berfirman: Artinya: "Sesungguhnya orang-orang beriman adalah bersaudara, damaikanlah di antara dua saudaramu jika ada persengketaan"

Nabi bersabda: "Sadakoh yang paling utama adalah mendamaikan dua orang yang bersengketa" (HR. Tabrani).

Sabda Nabi yang lain: "Bertakwalah kcpada Allah dan damaikanlah orangorang yang bersengketa sebab sesungguhnya Allah mendamaikan orang-orang beriman pada hari kiamat" "Tidaklah termasuk pendusta orang yang mengupayakan perdamaian di antara sesama manusia, ia menumbuhkan kebaikan atau mengatakan kebaikan" (Bukhari Muslim).

37 Ada hadis Nabi yang diriwayatkan oleh Baihaqi, Nabi bersabda: "Jika kamu berteman dengan seseorang maka bertanyalah tentang namanya dan nama ayahnya, 
n. Mempertahankan harga diri ikhwan dan menolong mereka meskipun sedang tidak di hadapan kita. ${ }^{38}$

o. Menunaikan janji apabila ia berjanji, sebab sesunggunya janji termasuk salah satu dari dua pemberian, menurut Ahlal-Sunnah, ia adalah utang. Menyalahi janji termasuk kemunafikan.

\section{E. Urgensi Dan Eksistensi Mursyid}

Urgensi dan eksistensi guru dalam suatu tarekat merupakan hal yang mutlak. Hal ini sebagaimana dijelaskan bahwa; tidaklah benar seseorang yang mengamalkan suatu tarekat tanpa guru. Guru tidak sekedar mengajarkan materi ajaran tasawuf tapi yang paling penting adalah melakukan talqin atau bai'at yang tidak bisa dilakukan oleh orang lain.

Menyangkut pentingnya guru dalam mengamalkan tarekat, al-Gazali menyatakan: Begitulah halnya seorang murid membutuhkan seorang mursyid atau guru sang penunjuk, yang membimbingnya pada jalan yang lurus. Sebab jalan keagamaan terkadang begitu samar-samar, dan jalan syetan begitu beraneka. Barangsiapa tidak punya sang penunjuk (mursyid) yang menjadi panutannya, dia akan dibimbing syetan ke arah jalannya. ${ }^{39}$ Hendaklah ia berpegang teguh kepada gurunya bagaikan pegangan seorang buta di pinggir sungai, dimana dia sepenuhnya menyerahkan dirinya kepada pembimbingnya, serta tidak berselisih pendapat dengannya. ${ }^{40}$

jika ia tidak ada engkau menjaganya, jika ia sakit engkau menengoknya, jika ia meninggal maka engkau pun menyaksikannya (ta ziah)".

Hadis yang lain berbunyi: Apabila seseorang mencintai temannya karena Allah maka kenalilah dia sebab hal itu lebih mengekalkan kasih sayang dan lebih meneguhkan kecintaan kepadanya". (HR. ImamAhmad, Bukhari).

38 Nabi bersabda: Tidaklah seorang muslim mempertahankan harga diri (kehormatan) saudaranya yang mulim, kecuali adalah hak bagi Allah membebaskan ia dari api neraka di hari kiamat". (HR.Ahmad dan Abu Dawud).

${ }^{39}$ Al-Ghazali. Ihya Ulumuddin. Cairo : Al-Bab Al-Halabi., t.tp., 1343 H., hlm.42

${ }^{40}$ Ibid., hlm. 6 


\section{F. Penutup}

Tarekat sebagai suatu organisasi di mana didalamnya diajarkan tentang tarekat, makas secara pasti dibutuhkan keberadaan mursyid yang akan meng-ajarkar tarekat kepada para muridnya.

Fungsi dan signifikansi mursyid dalam suatu tarekat sangatlah penting dan sangat dibutuhkan untuk mengantarkan para murid tarekat kepada hadirat Tuhan yang Maha Kuasa. Karena itu keberadaan mursyi dalam suatu tarekat sangat penting dan memiliki peran yang sangat sentral. Keberadaannya tidak bisa dinegasikan mengingat hanya mursyidlah yang bisa mengantarkan para murid kepada apa yang menjadi tujuannya yaitu berada sedekat mungkin dengan Allah SWT.

Cara pandang terhadap eksistensi mursyid yang demikian sentral. Terkadang membuat murid begitu mengidolakan mursyid bahkan dalam konteks yang lebih radikal, sampai pada tingkat mengkultuskan mursyid --yang jika dilihat dari sisi akidah Islamiyyah perlu dipertanyakan.

Penempatan mursyid yang berlebihan oleh murid kadang membuat murid terjebak pada hal-hal yamh secara akidaj perlu dikritisi. Karena jika tidak, maka dikhawatirkan akan menggiring para murid tarekat terseret ke dalam arus krmuysrikan. Dan ini tentu saja tidak baik banyak sangat berbahaya karena bisa mengarah pada syirik. Sedangkan syirik adalah perbuatan yang tidak akan diampuni oleh Allah SWT. 


\section{DAFTAR PUSTAKA}

Abi Abdillah, Shoheh Bukhari,al-Dar wa mathobi'i : Al-Sya'bi, Juz I, tt Abu al-Wafa al-Ganimi al-Taftazani, 1973, 'Ilm al-Kalām wa Ba'd Musykilātihi, Kairo : Dar al-Saqafah

Abuddinata., Akhlak Tasawuf dan karakter Mulia. Jakarta : PT. Raja Grapindo Persada. 2014

'Alaudin an-Naqsyabandy. Ma Huwa at-Tasawwuf wa Ma hiya atTariqah an-Naqsyabandiyyah. T.tp: tp., tt.,

Aboebakar Atjeh, Pengantar Ilmu Tarekat: Uraian-uraian tetang Mistik (Solo: Ramadhani, 1990).

Ahmad Zahro. Tradisi Intelektual NU: Lajnah Bahtsul Masa'il 19261999. Yogyakarta : LKIS. 2004.

Annemarie Schimmel, Dimensi Mistik Dalam Islam, Terjemahan oleh Supardi Djoko Damono dkk. Dari Mystical Dimension of Islam (1975), Jakarta: Pustaka Firdaus, 1986.

Cecep Alba,. Cahaya Tasawuf. Bandung : CV. Wahana Karya Grafika. 2009

---------,. Tasawuf dan Tarekat. Dimensi Esoteris Ajaran Islam. Bandung: PT Remaja Rosdakarya. 2014

Dewan Redaksi Ensiklopedi Islam. Ensiklopedi Islam 5. Jakarta: Ikhtiar Baru. 1997

H.A Mustofa. Akhlak Tasawuf. Bandung : Penerbit CV. Pustaka Setia. 1997.

H.A. Rivay Siregar, Tasawuf : Dari sufisme klasik Ke Neo -Sufistik. Jakarta : PT. Grapindo Raja Persada. 1999.

Harun Nasution, Islam Ditinjau dari Berbagai Aspeknya, Jilid II (Jakarta: U1 Press, 1978),

---------., Falsafah dan Mistisisme dalam Islam, (Jakarta: Bulan Bintang, 1986).

Jamil Shaliba, Al-Mu'jam al-Falsafi, Juz II, (Beirut: Dar al-Kitab, 1979)

Louis Ma'luf. Al-Munjid Fi Al-Lughah Wa Al-'Alam. Beirut : dar AlMasyrik. 1975

Samsul Munir Amin. Ilmu Tasawuf. Jakarta: Remaja rosdakarya. 2015.

Shihabuddin Suhrowardi. Bidayatussâlikin (Belajar Ma'rifat Kepada Allah). Ciamis : Yayasan Serba Bakti Pondok Pesantren Suryalaya Tasikmalaya. 
Solihin dan Rosihon Anwar. Ilmu Tasawuf. Bandung: Pustaka Setia.2011

TriminghamJ. Spencer, The Sufi Orders in Islam (London: Oxford University Press, 1973

Zaprulkhan. Ilmu Tasawuf Sebuah Kajian Tematik. Depok :. Raja Grapindo Persada. 2016. 